\title{
Diagnostic challenges of prolonged post-treatment clearance of Plasmodium nucleic acids in a pre-transplant autosplenectomized patient with sickle cell disease
}

\author{
Paul M. Luethy ${ }^{1}$, Sean C. Murphy ${ }^{2,3,4}$, Annette M. Seilie' ${ }^{2}$, Yingda L. Xie ${ }^{5}$, Chuen-Yen Lau ${ }^{5}$, John F. Tisdale ${ }^{6}$, \\ Matthew M. Hsieh ${ }^{6}$, Jessica L. Reinhardt ${ }^{1}$, Anna F. Lau ${ }^{1}$ and Gary A. Fahle ${ }^{1^{*}}$
}

\begin{abstract}
Background: Autosplenectomy, as a result of sickle cell disease, is an important risk factor for severe malaria. While molecular methods are helpful in providing rapid and accurate infection detection and species identification, the effect of hyposplenism on result interpretation during the course of infection should be carefully considered.

Case presentation: A 32-year old autosplenectomized Nigerian male with severe sickle cell disease was referred to the National Institutes of Health for allogenic hematopoietic stem cell transplant. Despite testing negative for malaria by both smear and PCR 2 weeks after arrival in the USA, the patient developed fever and diffuse bilateral lower rib cage and upper abdominal pain 2 weeks later and subsequently tested positive for Plasmodium falciparum. Parasitaemia was tracked over time by microscopy and nucleic acid tests to evaluate the therapeutic response in the setting of hyposplenism. The patient showed prompt resolution of patent infection by microscopy but remained positive by molecular methods for $>30$ days after treatment initiation.

Conclusion: While molecular testing can provide sensitive Plasmodium nucleic acid detection, the persistence of Plasmodium nucleic acids following adequate treatment in functionally asplenic patients can lead to a diagnostic dilemma. In such patients, clinical response and peripheral blood smears should guide patient management following treatment. Nonetheless, in pre-transplant patients at high-risk for pre-existing Plasmodium infections, highly sensitive molecular assays can be useful to rule out infection prior to transplantation.
\end{abstract}

Keywords: Plasmodium falciparum, Sickle cell disease, Autosplenectomy, PCR, RT-PCR, 18 S rRNA, NAAT, Nucleic acid amplification test

\section{Background}

Malaria remains a prominent cause of infection and mortality worldwide with $\sim 212$ million new infections in 2015 and almost 429,000 reported deaths [1]. Malaria transmission has been identified in 91 countries, with $90 \%$ of all cases and $92 \%$ of deaths occurring in subSaharan Africa. Sickle cell disease (SCD), which leads

\footnotetext{
*Correspondence: gfahle@cc.nih.gov

${ }^{1}$ Microbiology Service, Department of Laboratory Medicine, National Institutes of Health, 10 Center Drive, Bldg. 10, 2C306, Bethesda, MD 20892-1508, USA

Full list of author information is available at the end of the article
}

to haemolytic anaemia, acute vaso-occlusive events, and chronic end-organ damage, is also a serious cause of childhood mortality in sub-Saharan Africa [2]. Studies have shown that a heterozygous mutation in the $\beta$-globin allele can confer protection from severe malaria compared with the homozygous mutation due to reduced cytoadherence, increased sickling with subsequent changes in host cell biochemistry, and increased splenic clearance [3-6]. The presence of heterozygous sickle cell trait, however, does not prevent infection.

This case concerns a patient with SCD and autosplenectomy, who travelled from Nigeria to the USA to 
undergo allogenic haematopoietic stem cell transplantation (HSCT). Discussion points include the conundrum of initial negative malaria screening results, a subsequent diagnosis of Plasmodium falciparum malaria, and clinical considerations when faced with conflicting diagnostic test results post-treatment due to the persistence of Plasmodium nucleic acids in blood samples.

\section{Case presentation}

This is a case of a 32-year old Nigerian man with homozygous SCD. Despite receipt of hydroxyurea, he continued to experience monthly priapism and three to four hospitalizations for vaso-occlusive pain crises per year. He reported a history of several malaria infections including a severe episode that led to acute chest syndrome and heart failure requiring intensive care unit monitoring and red cell transfusions. The patient travelled from Nigeria to the USA (arriving on day-32) in preparation to receive a non-myeloablative allogeneic HSCT from his fully human leukocyte antigen-matched brother. As part of his pre-transplant evaluation on day-18 ( 2 weeks after entering the USA from Nigeria), blood was obtained for malaria thick and thin smears and for Plasmodium multiplex PCR; all testing was reported as negative. On day4 , the patient developed fever as well as diffuse bilateral lower rib cage and upper abdominal pain. He was admitted on day- 1 for a vaso-occlusive pain crisis. On day 0 , the patient developed fevers to $39.1^{\circ} \mathrm{C}$ and a decrease in absolute haemoglobin from 8.2 to $5.8 \mathrm{~g} / \mathrm{dL}$. Possible intraerythrocytic parasites were observed initially from routine cell count and differential smears, and repeat malaria blood smears were positive for immature (ring form) and mature trophozoites and schizonts of $P$. falciparum at $2.9 \%$ parasitaemia (Fig. 1). Parallel testing with a multiplex malaria PCR ([7-9]; limit of detection (LOD) defined as 700 parasites/mL of whole blood) was also positive (Fig. 2a). Treatment with artemether-lumefantrine $\left(20 / 120 \mathrm{mg}\right.$, Coartem $\left.{ }^{\circledR}\right)$ was started on day 1 after consultation with the clinical team and pharmacy. The patient was supported with RBC transfusions and defervesced by day 3 with $0.93 \%$ parasitaemia. Between days 5 and 6, his parasitaemia levels rose from 0.20 to $0.42 \%$, respectively (Fig. 2a). In response, he was immediately started on atovaquone/proguanil (Malarone ${ }^{\circledR}$ ) for 7 days

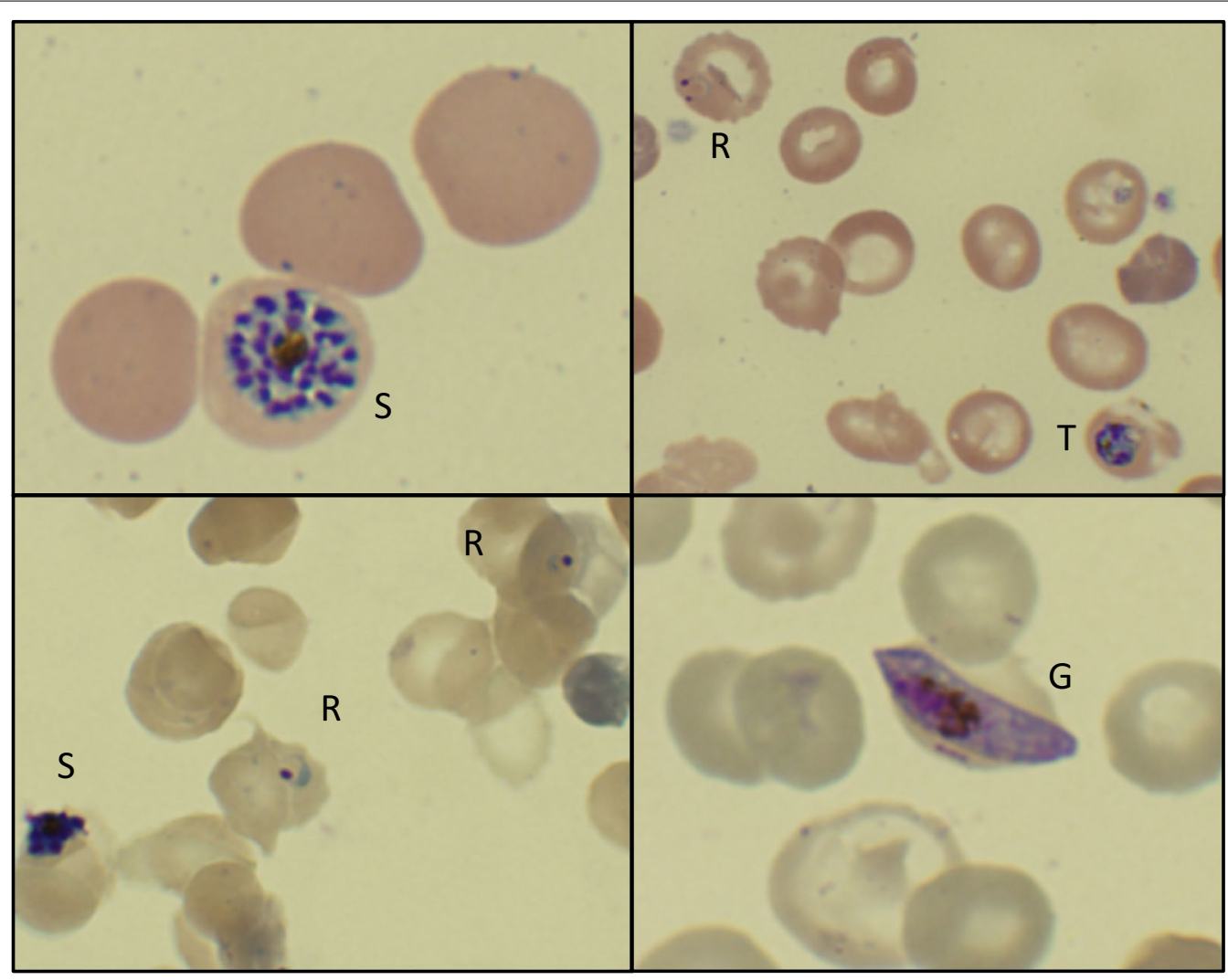

Fig. 1 Plasmodium falciparum forms observed in stained blood smears. Thin smears of peripheral blood with either Wright Giemsa (top) or Giemsa (bottom) staining. Parasite forms included immature trophozoites (rings, R), mature trophozoites (T), schizonts (S) and gametocytes (G). Pictured fields are representative of samples collected on day 0 (top panels and bottom left) and day 2 (bottom right) 


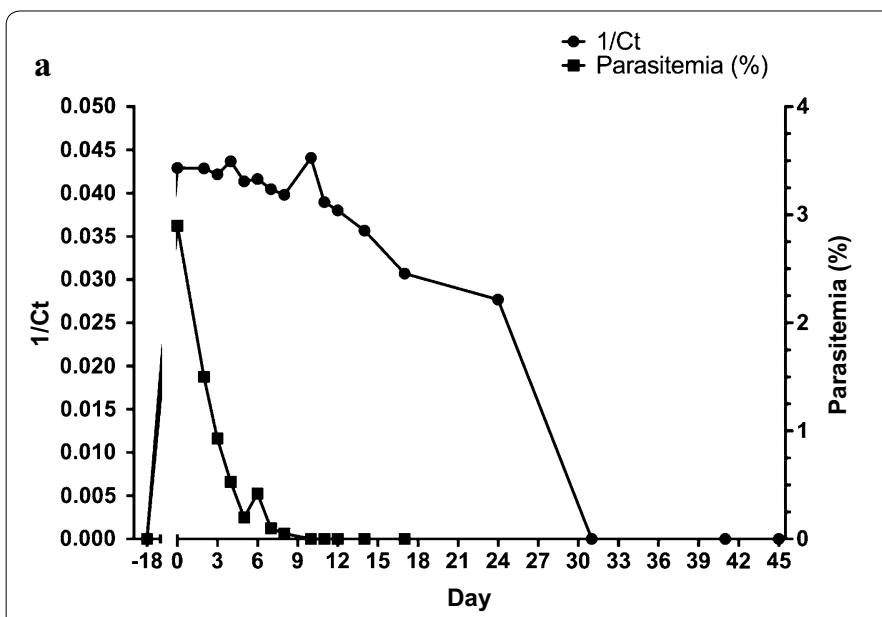

b

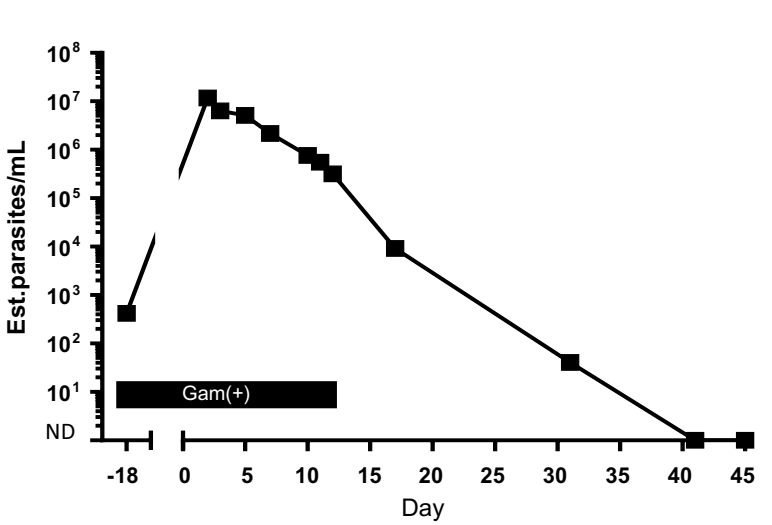

Fig. 2 Patient's course of microscopy and molecular PCR and qRT-PCR assay positivity. a Graphical correlation of microscopy-based parasitaemia $(\%$, right axis) with detection of Plasmodium DNA by a multiplex malaria DNA PCR assay (represented as 1/cycle threshold (1/Ct), left axis) from days-18 to 45. b Retrospective qRT-PCR performed on samples from days-18 to 45. Estimated (Est.) parasites/mL is based on the pan-Plasmodium $18 \mathrm{~S}$ rRNA channel; the black bar shows the date range where gametocyte mRNA was also qualitatively detected. Parasite burden on days 41 and 45 was below the limit of detection (not detected $[\mathrm{ND}]<20$ parasites $/ \mathrm{mL}$ )

due to concerns for artemether-lumefantrine resistance. Reflex testing by the Centers for Disease Control and Prevention did not reveal genetic markers on the kelch 13 gene that was consistent with artemisinin resistance. The patient remained clinically well with $<0.05 \%$ parasitaemia and was discharged after three doses of atovaquone/ proguanil (day 8). Blood smears were negative by day 10 , but the multiplex malaria PCR assay remained positive on day 17. Because of his scheduled transplant and slow parasite clearance, he received a course of doxycycline for 3 days. The multiplex malaria PCR assay became negative between days 25 and 31 . The patient proceeded with the allogeneic HSCT on day 41 and engrafted fully with donor red cells without recurrence of malaria during the transplant process. He has returned to Nigeria and has remained clinically well.

Retrospective testing was performed on 12 preserved whole blood samples using a quantitative reverse transcription PCR (qRT-PCR) that targets the highly expressed Plasmodium 18S rRNAs (LOD: 20 parasites/mL of whole blood [10, 11]). qRT-PCR demonstrated $\sim 420$ estimated parasites/mL of whole blood in the initial day-18 screening sample that was previously reported negative by peripheral blood smears and multiplex PCR (Fig. 2b). Parasite burden as measured by qRT-PCR decreased over time following treatment with positive results detected more than 1 month after treatment initiation. Additional molecular testing targeting the gametocyte-specific spliced PF3D7_0630000 mRNA [12] showed gametocyte detection on days-18 through
11 (Fig. 2b). Gametocyte load was highest at the peak of infection (days 0-5).

\section{Discussion and conclusion}

Timely detection of Plasmodium parasites in peripheral blood specimens is important for effective management of patients with suspected malaria infection [13]. Accurate species level identification along with detailed travel history are critical for determining appropriate anti-malarial therapy. Here, the characteristic microscopic structures of $P$. falciparum (immature trophozoite ring forms and occasional crescent-shaped gametocytes) along with the rarely present mature trophozoites and schizonts were observed (Fig. 1). The latter has been reported in patients without a functioning spleen, which is normally responsible for removing these mature forms [14].

Although serial blood smears and multiplex PCR demonstrated a response to treatment, blood smears correlated better with clinical improvement compared with PCR results (Fig. 2a). Prolonged PCR positivity resulted in two additional treatment courses with atovaquone/ proguanil and doxycycline (despite negative blood smears) to ensure complete eradication of $P$. falciparum prior to transplantation. In retrospect, the day-18 sample was positive using a highly sensitive Plasmodium $18 \mathrm{~S}$ rRNA qRT-PCR assay, indicating that the patient was infected prior to leaving Nigeria (Fig. 2b). Thus, while asymptomatic on initial presentation, the patient was incubating an unrecognized Plasmodium infection missed by both routine peripheral blood smears and 
multiplex PCR because the parasite burden $(\sim 420$ parasites $/ \mathrm{mL}$ ) was below the LODs for these assays (500020,000 parasites $/ \mathrm{mL}$ for thick blood smears by an expert reader [15] and 700 parasites/mL for the multiplex PCR). Molecular tests such as the qRT-PCR assay provide estimated parasite densities that correlate with microscopybased estimates [16]. Five days after treatment initiation, the qRT-PCR assay indicated that the parasite density decreased by $>80 \%$, which corresponded to clinical improvement. Despite a long period of qualitative molecular positivity, quantitative nucleic acid testing that are reflective of estimated parasite densities can help guide patient care.

The presence of mature parasite forms in peripheral blood smears and the delay in PCR clearance after treatment created a diagnostic challenge for clinicians. In this patient, these phenomena were most likely due to biological changes caused by the patient's underlying SCD. Normally, RBCs harbouring mature trophozoites and schizonts are often sequestered in organ microvasculature [17] due to the translocation of parasite proteins to the RBC surface that bind to ligands on the organ and tissue epithelial cell surface [18]. In individuals with SCD, this surface protein expression is decreased resulting in reduced cytoadherence of infected RBCs [19]. In this patient, however, autosplenectomy due to SCD was most likely the primary driver of this presentation [20-23].

In functionally asplenic patients like the patient presented here, it is likely that Plasmodium-derived nucleic acids persist in peripheral blood cells longer than in persons with normal spleens. This can lead to a diagnostic dilemma if molecular tests alone are used to monitor parasite clearance following treatment. In persons with normal splenic function, it is known that molecular assays can remain positive at low-levels following treatment beyond microscopically-apparent clearance of organisms [10]. In controlled human malaria infection (CHMI) studies, $\sim 50 \%$ of blood smear-positive persons rapidly become RT-PCR negative post-treatment and the others show substantial reductions in RT-PCR-measured parasite load; all subjects were RT-PCR negative 2-3 weeks later [10]. It is possible and likely that molecular positivity resolved earlier than the end of study time point, but no test-of-cure samples were collected during days 6-15 post-treatment [10]. Additional data regarding clearance of Plasmodium 18S rRNA is being accrued in multiple ongoing, unpublished CHMI studies (SC Murphy, pers. comm.). Regardless of splenic status, clinicians must consider whether ongoing molecular positivity in a treated patient is due to slower clearance of non-viable parasite-derived nucleic acids or represents a potential ongoing viable infection. Gradually-declining molecular assay-derived measurements of parasite density are most likely representative of non-viable, slow-clearing parasite biomass. In contrast, resurgent or clear positive persistence could represent impending treatment failure, which has been recognized for drug-resistant parasites manifesting as persistent PCR positivity in the week following initial treatment [21]. Thus, additional studies are needed to better understand the duration of molecular test positivity in appropriately-treated patients with or without a functional spleen. This information will be useful for guiding decisions about second-line treatments. In this case study, blood smears corresponded to the patient's clinical status. In pre-transplant patients with high-risk for pre-existing Plasmodium infections, highly sensitive molecular assays such as the ultrasensitive qRTPCR assay used herein may be useful for ruling out infection prior to transplantation. The LOD, range of species detected, and sample stability should be considered when selecting such tests.

\section{Abbreviations}

SCD: sickle cell disease; HSCT: hematopoietic stem cell transplantation; LOD: limit of detection; Ct: cycle threshold; PCR: polymerase chain reaction; RT-PCR: reverse transcription PCR; rRNA: ribosomal RNA.

\section{Authors' contributions}

$\mathrm{PL}, \mathrm{AL}$, and GF provided clinical laboratory interpretation and drafted the manuscript. SM provided RT-PCR testing and contributed to the manuscript. YE, CL, $\mathrm{JT}$, and $\mathrm{MH}$ provided patient care, clinical interpretation, and contributed to the manuscript. JR provided smear results. All authors read and approved the final manuscript.

\section{Author details \\ ${ }^{1}$ Microbiology Service, Department of Laboratory Medicine, National Insti- tutes of Health, 10 Center Drive, Bldg. 10, 2C306, Bethesda, MD 20892-1508, USA. ${ }^{2}$ Department of Laboratory Medicine, University of Washington, Seattle, WA 98109, USA. ${ }^{3}$ Department of Microbiology, University of Washington, Seattle, WA 98109, USA. ${ }^{4}$ The Center for Emerging and Re-emerging Infectious Diseases, University of Washington, Seattle, WA 98109, USA. ${ }^{5}$ National Institute of Allergy and Infectious Diseases, National Institutes of Health, Bethesda, MD 20892, USA. ${ }^{6}$ Molecular and Clinical Hematology Branch, National Heart, Lung, and Blood Institute, National Institutes of Health, Bethesda, MD 20892, USA.}

\section{Acknowledgements}

The medical technologists in the Molecular Diagnostics section of the Microbiology service are acknowledged for performing the multiplex Plasmodium PCR assay as is Thomas Wellems (Chief, LMVR, NIAID, NIH) for his critical review of this manuscript. The authors also thank the UW Center for AIDS Research Clinical Research and Retrovirology Core (Al27757).

\section{Competing interests}

The authors declare that they have no competing interests.

Availability of data and materials

Not applicable.

Consent for publication

$\mathrm{NIH}$ consent to publish was obtained from the patient.

Ethics approval and consent to participate

Ethics approval and consent to participate is included in $\mathrm{NIH}$ research protocol 03-H-0170 (clinicaltrials.gov) 


\section{Funding}

This work was supported by the Intramural Research Program of the National Institutes of Health and the University of Washington Department of Laboratory Medicine. The content is the responsibility of the authors and does not represent the official views of the National Institutes of Health.

\section{Publisher's Note}

Springer Nature remains neutral with regard to jurisdictional claims in published maps and institutional affiliations.

Received: 30 June 2017 Accepted: 23 December 2017

Published online: 10 January 2018

\section{References}

1. WHO. World malaria report. Geneva: World Health Organization; 2016

2. Grosse SD, Odame I, Atrash HK, Amendah DD, Piel FB, Williams TN. Sickle cell disease in Africa: a neglected cause of early childhood mortality. Am J Prev Med. 2011:41:S398-405.

3. Gong L, Parikh S, Rosenthal PJ, Greenhouse B. Biochemical and immunological mechanisms by which sickle cell trait protects against malaria. Malar J. 2013;12:317

4. Aidoo M, Terlouw DJ, Kolczak MS, McElroy PD, ter Kuile FO, Kariuki S, et al. Protective effects of the sickle cell gene against malaria morbidity and mortality. Lancet. 2002;359:1311-2.

5. Luzzatto L. Sickle cell anaemia and malaria. Mediterr J Hematol Infect Dis. 2012:4:e2012065.

6. McAuley CF, Webb C, Makani J, Macharia A, Uyoga S, Opi DH, et al. High mortality from Plasmodium falciparum malaria in children living with sickle cell anemia on the coast of Kenya. Blood. 2010;116:1663-8.

7. Rougemont M, Van Saanen M, Sahli R, Hinrikson HP, Bille J, Jaton K. Detection of four Plasmodium species in blood from humans by $18 \mathrm{~S}$ rRNA gene subunit-based and species-specific real-time PCR assays. J Clin Microbiol. 2004:42:5636-43.

8. Perandin F, Manca N, Calderaro A, Piccolo G, Galati L, Ricci L, et al. Development of a real-time PCR assay for detection of Plasmodium falciparum, Plasmodium vivax, and Plasmodium ovale for routine clinical diagnosis. J Clin Microbiol. 2004;42:1214-9.

9. Seder RA, Chang LJ, Enama ME, Zephir KL, Sarwar UN, Gordon IJ, et al. Protection against malaria by intravenous immunization with a nonreplicating sporozoite vaccine. Science. 2013:341:1359-65.
10. Murphy SC, Prentice JL, Williamson K, Wallis CK, Fang FC, Fried M, et al. Real-time quantitative reverse transcription PCR for monitoring of bloodstage Plasmodium falciparum infections in malaria human challenge trials. Am J Trop Med Hyg. 2012;86:383-94.

11. Billman ZP, Seilie AM, Murphy SC. Purification of Plasmodium sporozoites enhances parasite-specific CD8+ T cell responses. Infect Immun. 2016:84:2233-42.

12. Hanron AE, Billman ZP, Seilie AM, Olsen TM, Fishbaugher M, Chang $M$, et al. Multiplex, DNase-free one-step reverse transcription PCR for Plasmodium 18S rRNA and spliced gametocyte-specific mRNAs. Malar J. 2017;16:208.

13. Suh KN, Kain KC, Keystone JS. Malaria. CMAJ. 2004;170:1693-702.

14. Buffet PA, Safeukui I, Deplaine G, Brousse V, Prendki V, Thellier M, et al. The pathogenesis of Plasmodium falciparum malaria in humans: insights from splenic physiology. Blood. 2011;117:381-92.

15. Chiodini PL. Malaria diagnostics: now and the future. Parasitology. 2014;141:1873-9.

16. Murphy SC, Hermsen CC, Douglas AD, Edwards NJ, Petersen I, Fahle GA et al. External quality assurance of malaria nucleic acid testing for clinical trials and eradication surveillance. PLoS ONE. 2014:9:e97398.

17. Cowman AF, Healer J, Marapana D, Marsh K. Malaria: biology and disease. Cell. 2016;167:610-24.

18. Hviid L, Jensen AT. PfEMP1 — a parasite protein family of key importance in Plasmodium falciparum malaria immunity and pathogenesis. Adv Parasitol. 2015;88:51-84.

19. Cholera R, Brittain NJ, Gillrie MR, Lopera-Mesa TM, Diakite SA, Arie T, et al. Impaired cytoadherence of Plasmodium falciparum-infected erythrocytes containing sickle hemoglobin. Proc Natl Acad Sci USA. 2008;105:991-6.

20. Demar M, Legrand E, Hommel D, Esterre P, Carme B. Plasmodium falciparum malaria in splenectomized patients: two case reports in French Guiana and a literature review. Am J Trop Med Hyg. 2004;71:290-3.

21. Chotivanich K, Udomsangpetch R, McGready R, Proux S, Newton P, Pukrittayakamee $\mathrm{S}$, et al. Central role of the spleen in malaria parasite clearance. J Infect Dis. 2002;185:1538-41.

22. Buffet PA, Safeukui I, Milon G, Mercereau-Puijalon O, David PH. Retention of erythrocytes in the spleen: a double-edged process in human malaria. Curr Opin Hematol. 2009;16:157-64.

23. Greenwood T, Vikerfors T, Sjoberg M, Skeppner G, Farnert A. Febrile Plasmodium falciparum malaria 4 years after exposure in a man with sickle cell disease. Clin Infect Dis. 2008:47:e39-41.

\section{Submit your next manuscript to BioMed Central and we will help you at every step:}

- We accept pre-submission inquiries

- Our selector tool helps you to find the most relevant journal

- We provide round the clock customer support

- Convenient online submission

- Thorough peer review

- Inclusion in PubMed and all major indexing services

- Maximum visibility for your research

Submit your manuscript at www.biomedcentral.com/submit
Ciomed Central 